\title{
THE ISSUE OF SUBTITLING HUMOR IN ARABIC
}

\author{
Abdelouahab Elbakri \\ Dr., University of Ibn Zohr, \\ Agadir, Morocco
}

\begin{abstract}
:
Subtitling humor is one of the most arduous tasks subtitlers face as it involves technical, linguistic, textual and cultural factors. This article aims at investigating the issue of manipulating humor in Arabic subtitles of American series and movies. It examines the strategies subtitlers use in translating humor and analyzes the solutions they opt for. It focuses on two fields of study: jokes and puns. The study is based on the work of Diaz Cintas (2012) and (2007) on ideological manipulation in Audiovisual Translation (AVT). The theory stipulates that translators have turned into intercultural agents and mediators shaping the ideological discourse of their culture.
\end{abstract}

Keywords: AVT, subtitling, manipulation, strategies, humor, joke, pun

\section{Introduction}

In AVT, a lot of manipulative practices are resorted to when the moral values and principles of the audience are threatened; let alone in the context of our study. It is taken for granted that the values of the source text (American) largely differ from those of the target text (Middle Eastern). The idiosyncrasies of both cultures make the translator's attempts to mediate a tremendously arduous task.

Since World War II, and with the advent of mass media communication especially TV and the internet, the American culture has achieved a considerable leap in the freedom of verbal interaction. The concepts of politeness/impoliteness, vulgarity/ decency or morality/immorality have evolved and taken an unconventional turn. According to Locker and Watts (2005: 10), they have become "discursive concept[s] arising out of interactants' perceptions and judgments of their own and others' verbal behavior". These perceptions and judgments are manipulated by the media and their filters have become very low. Accordingly, a considerable number of the taboos that hinder people's liberty of speech are lifted and people have found themselves free to swear, curse and use 'inappropriate' language almost without any constraints, especially in humor. In contrast, the Middle Eastern culture is highly governed by norms. These socio-cultural constraints have as a primary role to govern behavior and ensure social order (Toury, 1995). They are highly influenced and monitored by the Islamic religion and tribal values which decide on what is appropriate or inappropriate, polite or impolite, moral or immoral, etc. The question then is: how

iCorrespondence: email abdelouahabelbakri@gmail.com 
can mediation be achieved in such an incongruous translation context? In the following article we will discuss some techniques of manipulation that subtitlers use when the morals and values of the target culture are at stake. Our discussion will cover the field of humor given that it is mostly based on vulgarity, immorality and the excessive use of taboo language.

\section{Defining humor}

Humor is originally a Latin word. It refers to one of the different moods that a human being can be in. Díaz Cintas and Remael (2007: 212) cite the definition of the term as suggested by MacMillan English Dictionary for Advanced Learners (2002: 702) "the quality that makes a situation or entertainment funny: a novel full of humor." Attardo (1994: 3) argues that some scholars do not believe that an "all-embracing definition" of humor could be formulated. He claims that "linguists, psychologists and anthropologists have taken humor to be an all-encompassing category, covering any event or object that elicits laughter, amuses or is felt to be funny" (ibid.:4). Newmark (2003: 126) considers humor "as - a generic term for mirth, laughter and smiling. It has elements of the surprising, the unusual, the irregular and the absurd. It is evinced in vocal sound and/or facial expression." However, our main concern, in this article, is verbal humor produced by means of linguistic exchange.

Researchers in the field have tried to establish taxonomies to classify verbal humor: (Monro, 1953); (Goldstein and McGhee, 1972); (Zijderveld, 1983); (Morreall, 1983); (Feigelson, 1989); (Norrick, 1993); (Zabalbeascoa, 1996); (Alexander, 1997). Dynel (2009) suggests the following taxonomy of humor: jokes, conversational humor, lexemes and phrasemes, witticisms (including stylistic figures, puns, allusions, and register clash), retorts, teasing, banter, putdowns, self-denigrating humor and anecdotes. For the present article we will mainly be concerned with two types: jokes and puns.

\section{Subtitling humor}

Translating humor has always been considered risky if not relatively impossible as humor is culturally bound. Leibold (1989: 109) posits that the task of translating humor is threefold. First, the translator has to accurately decode the humorous speech in the source culture. This decoding requires a perfect knowledge of the culture as of its "rules, expectations, solutions and agreements" (Vandaele 2010: 149). Then, the translator needs to transfer that speech in a different and often incongruent linguistic and cultural environment. And finally, this transferred text has to be reformulated in a new speech which effectively recaptures the intention of the original humorous message and evokes in the target audience a similar effect of laughter and enjoyment.

Subtitling humor is even more challenging. Asimakoulas (2004: 840), states that the subtitling of humor requires a translator to be creative and have humorous sensitivity that enables him/her to overcome the problems posed by different types of humor such as wordplay and parody. Kostovč́k (2009:175) states that subtitling is limited by the medium it is functioning in, and it does not allow the creation of a complete translation of the written version of speech due to its temporal and spatial constraints. As a constrained translation governed by a multitude of technical and linguistic limitations, keeping the funny effect on the target viewer "requires 
insight and creativity [and] establishing priorities" (Díaz Cintas and Remael, 2007: 214). According to Zabalbeascoa (1997 cited in Díaz Cintas and Remael, 2007):

"[I]t would seem that there is often a need to strike a balance between a search for comic effect by making the translated jokes as funny as possible, on the one hand, and, on the other, finding solutions that will not put the viewer off because [...] the plot, structure and the coherence of the text are weakened for the sake of certain witty one-liners." (215)

Translators have to render the English spoken text (the script) into standard written subtitles. Standard varieties are used in subtitling mainly for two reasons:

- the simplification and clarification of dialog, particularly that spoken in non-standard language,

- the impulse to maintain conformity with the usage of the standard variety as the norm in written texts.

Diaz Cintas and Remael (2007: 185) adhere to this view and claim that "most subtitles display a preference for conventional, neutral word order and simple well-formed stereotypical sentences." They are more concerned "with clarity, readability, and transparent references." Subtitles tend to use a standard form of language for the sake of clarity and accessibility to different types of viewers regardless of their idiosyncrasies.

In addition to these intricate difficulties, another issue raises when ideology is at stake. The subtitler uses manipulation maneuvers in order to make the audience accept the translation and avoid any cultural shock that could offend their beliefs and conventions. In the present article, we will discuss how subtitlers use manipulative strategies to meet these objectives.

\section{Díaz Cintas and Remael's strategies of culture bound terms}

Cintas (2012) identifies two types of manipulation in AVT: technical and ideological manipulations. Technical manipulation refers to the changes and modifications that an audiovisual text undergoes in order to meet technical needs and considerations. In other words, it is "a need to change the source text in order to respect lip-sync in dubbing or having to condense it so that it will fit in a given subtitle" (284). For example, in subtitling, reduction, condensation or deletion are manipulative techniques that are used by translators to cope with certain technical constraints. Gottlieb (2005: 52) argues that not to resort to such manipulative techniques may "result in poor translation". Ideological manipulation in AVT, on the other hand, refers to the intentional alterations that the target text has undergone and which have meant to unbalance its relationship with the source text. This can be driven by many factors inter alia political, religious, moral or economic.

Díaz Cintas and Remael (2007) provide a detailed set of strategies based on Díaz Cintas (2003) and Santamaria Guinot (2001). These strategies are the ones we shall adopt in this study to help us analyze how culture bound words are ideologically manipulated, given that taboo words are a good representation of this category of words. Ranzato (2013:101) argues that Díaz Cintas and Remael's strategies have "the merit of being both detailed and agile enough to serve as a 
valid tool for analysis, due to the absence of encumbering subdivisions and to the presence of well-defined clarifications." These strategies are comprehensive as they include a broader scope of contexts and cases. Here they are:

1. Loan: the word or phrase of the ST is borrowed by the TT and left unaltered, for example: food (muffin), drinks (cognac), places (San Francisco), historical events (perestroika)...

2. Calque: it is a literal translation of a CB terms, especially when an exact equivalent in the TL is not available, for example: the Spanish title Secretario de Estado is a calque translation of Secretary of State, while Ministro de Asuntos Exteriores (Minister of Foreign Affair)] would be more appropriate.

3. Explicitation: the translator tries to make the text more accessible by meeting the target audience half way, either through specification by using a hyponym (tulip for flower) or through generalization by using a hypernym (Belgian quality paper for Le Soir)

4. Substitution: a term is substituted with another one which is deviated from the source one because of technical constraints. A long reference that could be translated literally may be substituted by a shorter one to gain space and save reading time (stew for Goulash).

5. Transposition: the cultural concept is replaced by another cultural concept belonging to another culture (the Dutch HEMA for The British Marks \& Spencer).

6. Lexical recreation: it is the creation of a neologism, which may be inevitable if in the ST there is a made-up word as well. (the Spanish neologism rarezametro [oddity-meter]for the English 'weird shit-o-meter')

7. Compensation: it is compensating a loss somewhere in the translation of an exchange by over-translating or adding something in another. It is "popular strategy in subtitling even though it may not always be practical due to the oral-visual cohabitation of the source and target languages"(Diaz Cintas and Remael, 2007: 206).

8. Omission: though it is not an appropriate strategy, but it is sometimes unavoidable either because of space-time constraints or because there is no corresponding term in the TL.

9. Addition: it occurs when CBT might cause comprehension problems. (candidat Palantine for Palantine).

\section{Case study}

Using the strategies set above, we are going to analyze how subtitlers try to manipulate the texts that affront the Middle Eastern viewers and violate their moral and cultural norms and values. This study takes into consideration two types of humor: jokes and puns.

\subsection{Manipulating jokes}

The first humorous scenes that we shall analyze are taken from one of the most hilarious American series, Friends 


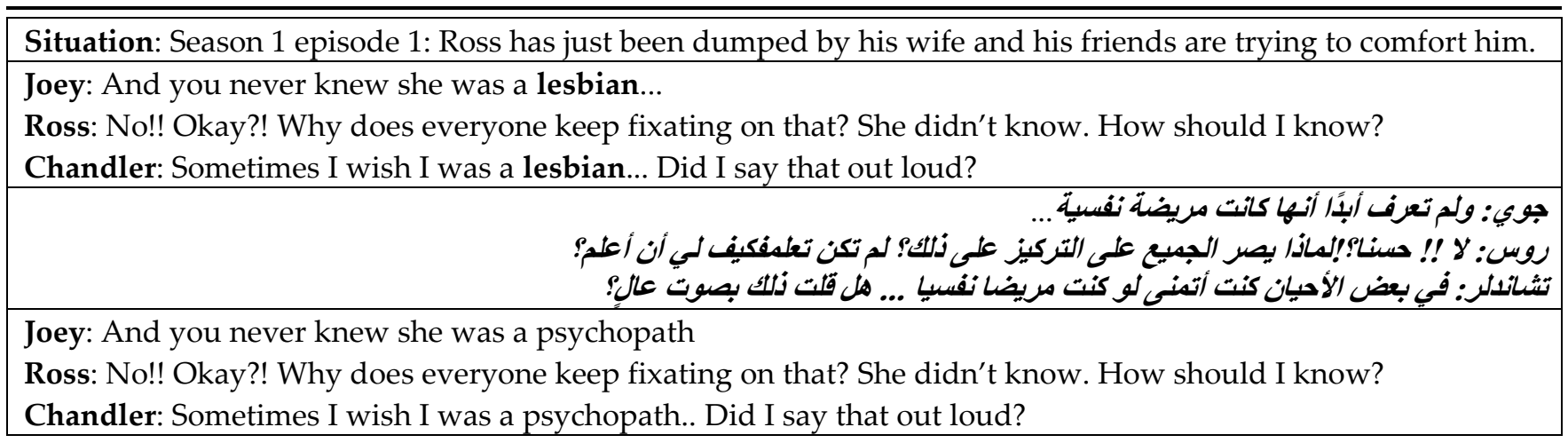

The ex-wife of Ross, Gabrielle, leaves him for a woman when she suddenly discovers that she is a lesbian after nine years of marriage. We realize that it is a weird situation even in the American culture from the reaction of the friends. It is rendered a joke and the group starts to tease Ross. The funny side of the story is that they have been married for a long time and neither Ross nor Gabrielle knew about it. In another funny scene, he says:

Ross: This was Carol's favorite beer. She always drank it out of the can, I should have known.

If that is shocking for the American audience, how do we expect Arab viewers to react vis-a-vis a situation with which they are totally unfamiliar? It is unconceivable that a woman leaves her man for another person, let alone that person should be a woman. So, the appalling issue for them is not knowing, but rather 'leaving the man' and 'being a lesbian'. That is why; the translator decides to take a side and instead of translating 'lesbian' into the Arabic words مثلية he decides to use the expression مريضة نفسية which literally means 'psychiatric patient'. This is a moral judgment more that a translation. It is meant to manipulate the audience by consolidating their cultural background which considers such an act scandalously unethical and at the same time by ignoring the humorous image of the scene which stems from on the 'unethical event'.

In sitcoms, like friends, the live laugh tracks which are part of the original production audio are indicators that designate the degree of humorosity each scene may have. The length and intensity of laughter reflect the expected reaction of the audience to the joke. Sometimes the laughs are joined with applauds and cheering to highlight the funniest sequences of the work. For the above scene, the laugh track indicates that the joke is really funny. Yet, the manipulative use of the expression مريضة نفسية deprives the scene of any aspect of humor.

Another scene with similar cheering laughs and applauds take place some episodes later.

Situation: Season1 episode 5. Joey convinces Monica to have dinner with a couple who he pretends to be brother and sister (which they are not)

Monica: Oh my god.

Joey: What?

Monica: Hello! Were we at the same table? It's like... cocktails in Appalachia.

Joey: Come on, they're close.

Monica: Close? She's got her tongue in his ear.

Joey: Oh, like you've never gotten a little rambunctious with Ross. 


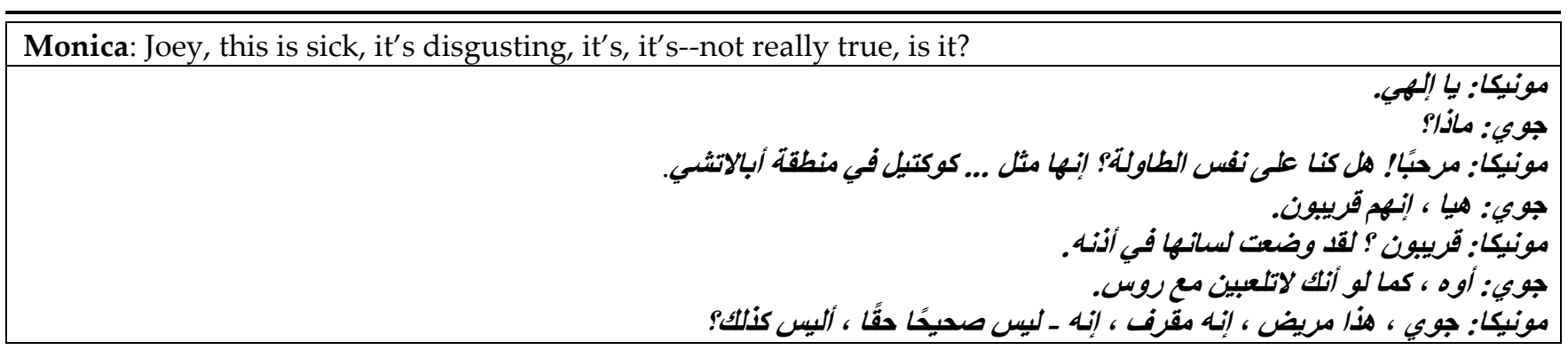

The laugh indicator shows that the scene is supposed to be very funny. It is the expression 'It's like... cocktails in Appalachia' which is the humorous side of the joke. The phrase 'cocktails in Appalachia' refers in the American culture to incest. Here, the subtitler applies the strategy of loan which does not provide the audience with any clue to understand the meaning of the phrase and recognize the joke, while the strategy of addition could have been a perfect means to put the viewer in the context. This intentional use of the strategy of loan allows the subtitler to hide the reference of incest implied in the joke. Yet, we notice from the reaction of Monica, that the idea is unacceptably 'sick' and 'disgusting'; which means that the joke, according to the American culture, springs from the reference to this taboo relationship condemned by all heavenly and earthly convictions. Americans agree that the joke is tolerable as far as it is incongruous, benign and reconcilable. This means that though the audience may be disgusted by the moral violation of the joke, they should consider it simultaneously benign and seek reconciliation with its reality. However, this violation of norms is not cross cultural. The 'benign' factor is culture bound and represents a real challenge to translators, as we have seen in the above scene. The translator manipulatively disregards the translation of the phrase 'cocktails in Appalachia' because the offense it embodies to the Arab viewer's culture cannot justify the humorous side of the joke.

In the next joke, the manipulation is again justified by the sexual reference it may call to the mind of the audience.

Situation: season 8 episode 12. Chandler is at home playing with his gambling machine

Chandler: I got good. I played this game all day and now I rule at it. They should change the name of it to Mrs. Chandler.

تشاندلر: لقلد تحسنت. لقد لعبت هذه اللعبة طوال اليوم والآن أحكمها. يجب أن يغيروا اسمها إلى الآنسة تثاندلر.

Chandler: I got better. I played this game all day and now I rule at it. They should change its nameto Miss Chandler.

Chandler teasingly refers to the machine as his wife implying that they perfectly know each other. He uses the title 'Mrs'. It is the title people use before a surname or full name to address or refer to a married woman. The subtitler, on the other hand, uses another title before 'Chandler': الآنسة which, in English, means 'Miss'. In the title 'Mrs', there is an insinuation that both Mr and Mrs Chandler are in a relationship of marriage which is exacerbated by the way Chandler talks about it. To avoid any insinuation to the sexual relationship between $\mathrm{Mr}$ and $\mathrm{Mrs}$ Chandler, the subtitler decides to use الآنسةinstead which changes the relationship into a brother - sister and wipes out any allusion to the sexual connotation the term 'Mrs' carries.

Another example of manipulating jokes is taken from another scene in Friends series. 


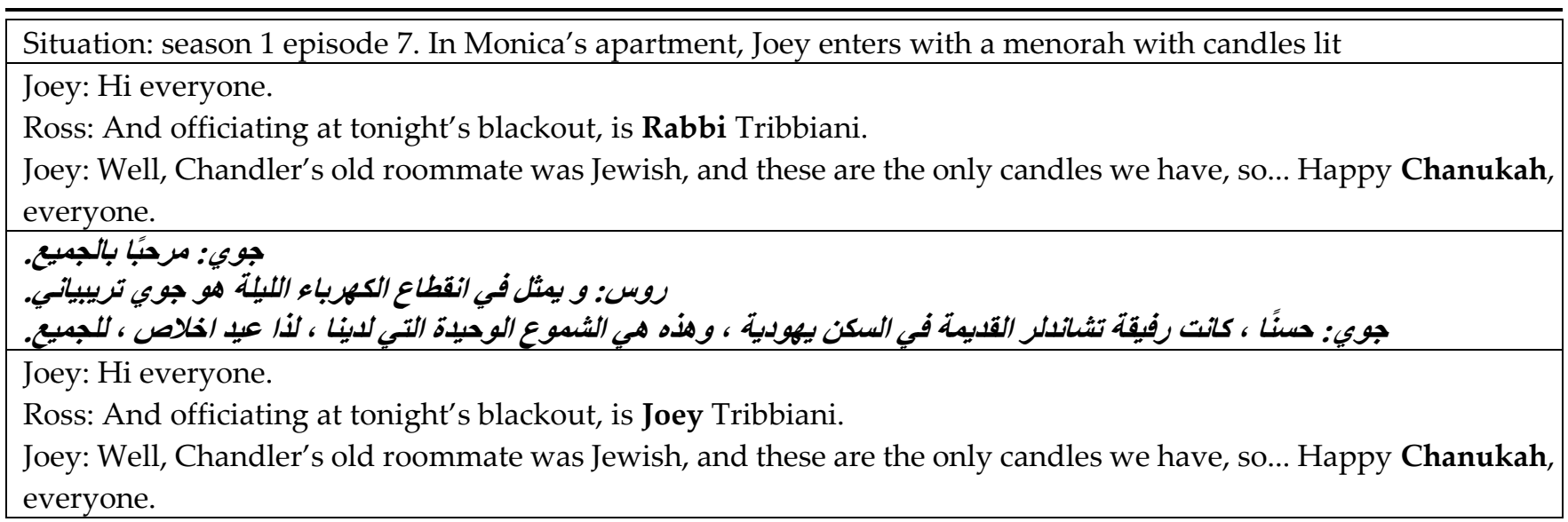

In this episode, the city is under a total blackout. The friends are gathered at Monica's apartment. Joey enters holding a menorah, which is an eight branch candelabrum used in Jewish worship. Ross immediately makes a joke at the sight of Joey carrying the menorah with the seven candles lit. He portrays his friend as a rabbi officiating some Jewish ritual. Joey takes part in the joke and plays the role of the rabbi blessing the worshipers and wishing them happy Chanukah. The joke is associated with the Jewish culture. We can identify two culture bound terms: rabbi and Chanukah. A rabbi is a Jewish preacher and a teacher of Judaism, while Chanukah or Hanukah is the Jewish eight-day, wintertime festival of lights, celebrated with a nightly menorah lighting, special prayers and fried foods. According to the translator's judgment, these terms may not be welcomed by the Arab audience as they stir feelings of antagonism and hatred. So, manipulative strategies are opted for to subtitle this sequence. For the term rabbi, the subtitler chooses to omit it at once and substitute it with Joey's first name: 'Rabbi Tribbiani' turns into ' جوي تريييانس' avoiding thus the use of the Arabic word $ح ا خ ا م$ 'Chich is culturally and religiously likely to evoke negative reactions. Concerning the word 'Chanukah', I personally cannot identify the strategy applied here. Chanukah in Arabic is translated عيد الأنوار. However, in the screen we can clearly read 'عيد إخلاص' which does not at all fit in this context. I believe that the translator has deliberately chosen to make a mistake at the translation of the Jewish celebration by inventing a term that does not exist at all. The result again is the loss of the sense of humor provided by the joke since it is based on two taboo words in the Arab context, namely 'rabbi' and 'Chanukah'.

The next joke is taken from the movie Mother's day. It presents another example of manipulation of humorous conversations.

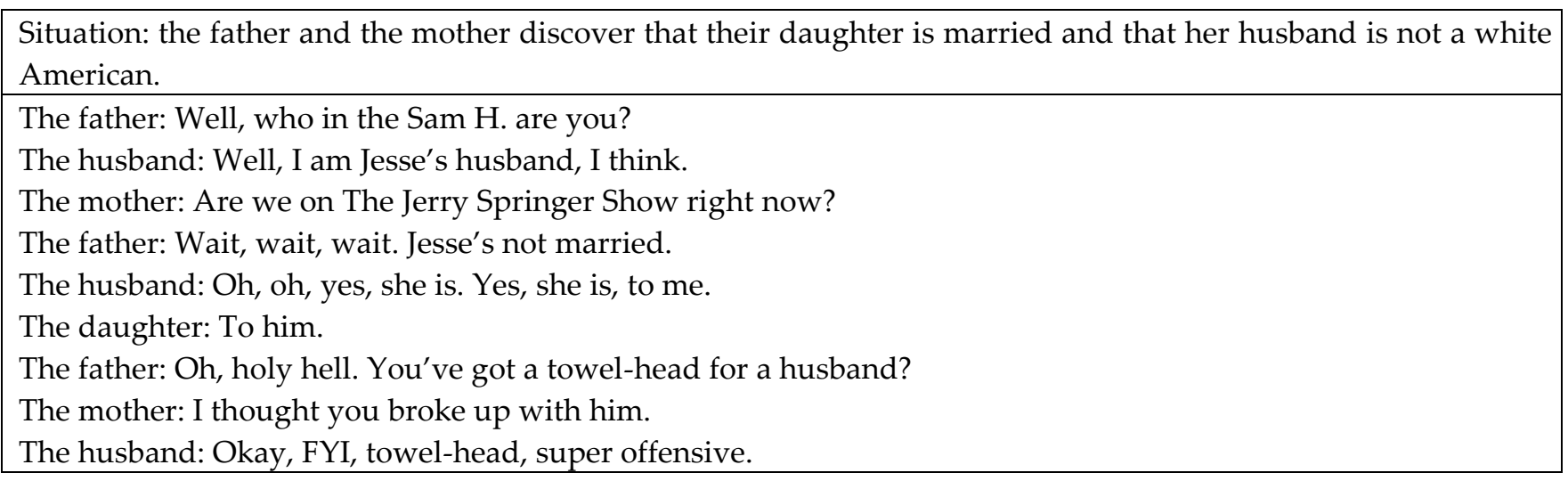




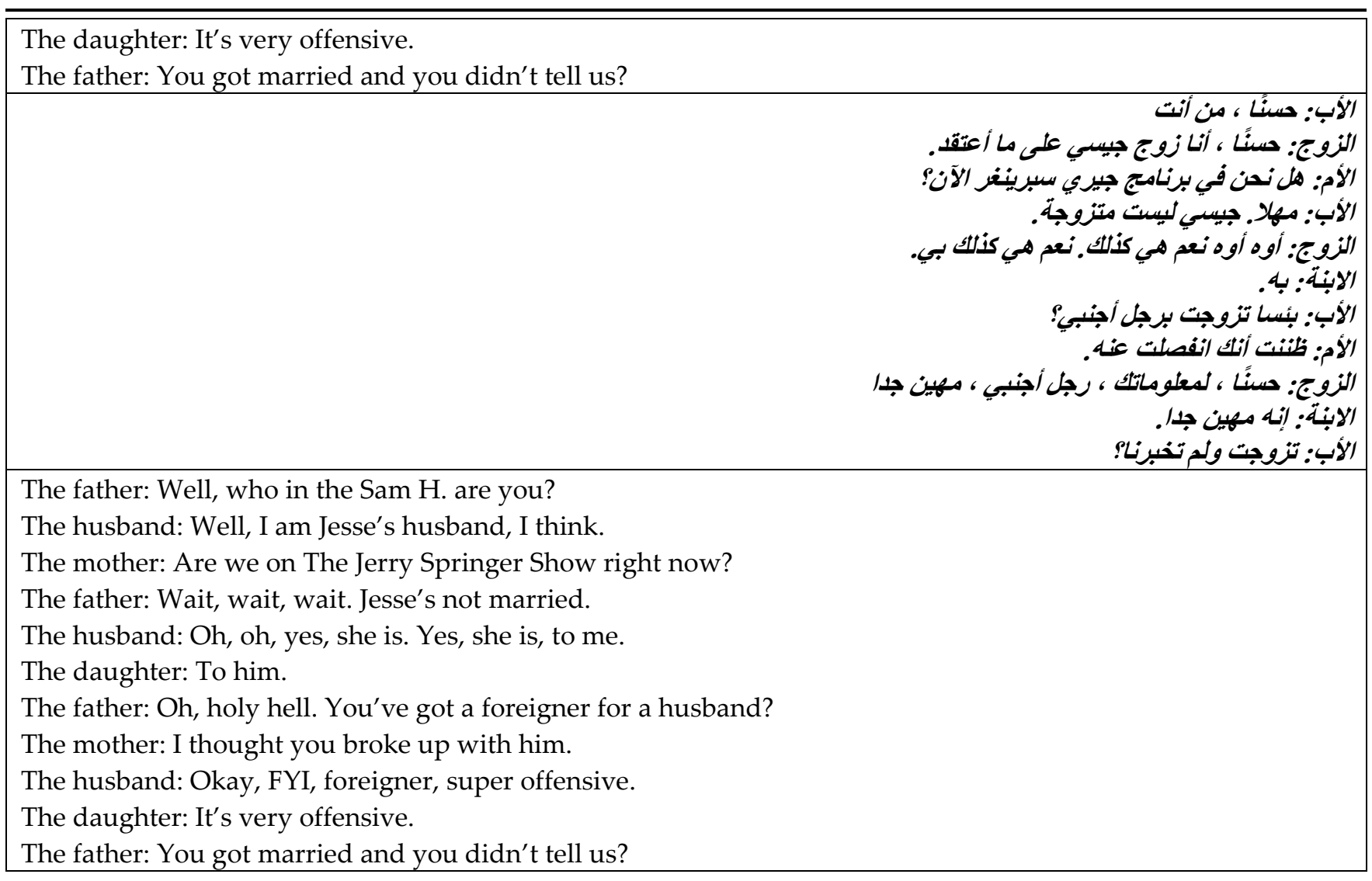

The scene features an old white American couple who have beliefs and principles that can shock the audience. They are white Americans and they want their daughters to marry good white American husbands and they loathe anything that could tarnish the whiteness and conformity of their 'Americanness'. When his daughter, Jess, suggests the beer names 'Hoegaarden, Stella and Kingfisher', the father replies: 'It sounds like the freakin' United Nations.' His use of the word 'freaking' reflects his xenophobia. And when he meets his son in law, Russell, for the first time he asks: 'Are you the houseboy?' Just because of his unwhite color, the husband, a doctor by profession, is associated with a low job, house-serving /slavery

In the exchange above, the father calls Russell a 'towel-head'. This expression is a derogative racist nomination for middle-eastern people. It is used for Arabs and Indians who cover their heads with a cloth/towel. It is mostly used to indicate any brown person who is Arab like. Russell qualifies this description as 'very offensive' as it is not politically correct. Being aware of this fact, the subtitler applies the technique of substitution, so instead of 'towel head', the Arabic word ' جنبي is used. The audience that the subtitles target is middle-eastern and can be offended by the racist description. However, by this substitution, the joke loses its amusing aspect and the exchange turns into a mere banal dispute void of any sense of humor.

\subsection{Manipulating puns}

Puns or wordplays are among the thorniest issues in translation especially in subtitling. Gottlieb (1997: 216) argues that trying to subtitle puns usually results in a failure. He attributes the complexity to three factors: language-specific constraints, media-specific constraints, and human 
constraints related to the person of the subtitler. Hereinafter, we shall consider some scenes where puns are used. The first one is taken from Friends series.

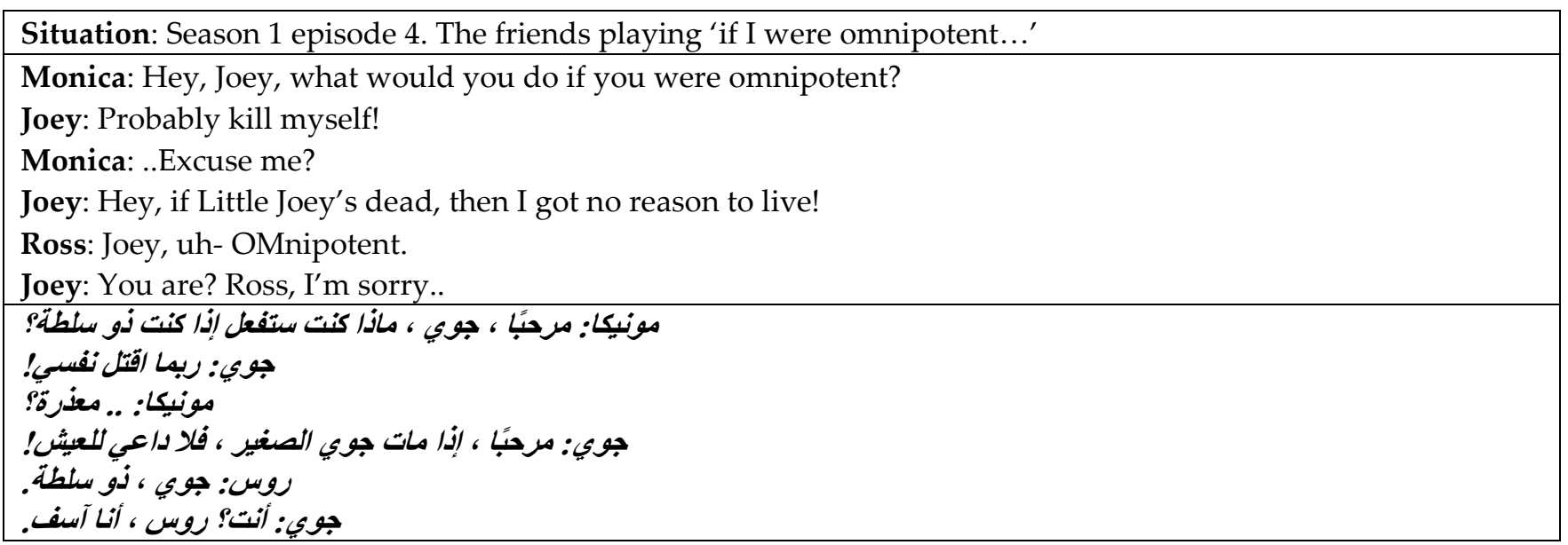

The live laugh tracks which are included in this scene indicate that the exchange must be extremely humorous, but, unfortunately, the subtitles are far from reflecting that. The translator faces the challenge of finding a corresponding counterpart for the terms 'omnipotent and impotent' which actually form the pun. The challenge is twofold: cultural and linguistic. In the Arab culture, Omnipotence is associated to God and can never be attributed to people even in an if-game. It would literally mean: what would you do if you were God. Instead of translating omnipotent by the accurate word القدير, the subtitler uses ذو سلطة meaning 'influential or powerful' which does not meet the denotation expressed in English. That is why; the word play is totally missed since it is done on the root ' potent'. The same effect could have been achieved had the subtitler played on the root 'قلر By doing so, both the pun and humor are lost.

We shall provide another example of puns in the series which uses again 'the ignorance/naivety' of the character as a source of humor. The role of the ignorant/naive is often played by Joey or Phoebe who seem to be the least intelligent in the group and who most of the time cannot follow up with the four others who are at varying degrees smarter and wittier. In this wordplay, Joey is not able to understand the word 'unisex'.

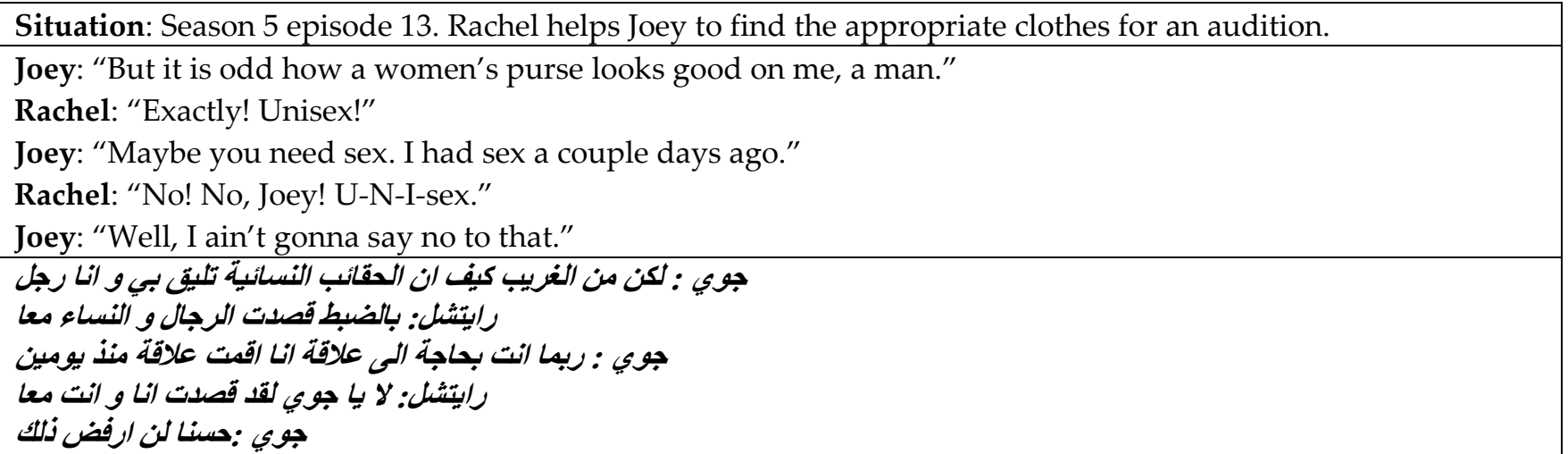


The wordplay is on the word 'unisex' as Joey cannot realize its meaning and mishears for 'you need sex'. Rachel tries to help by spelling the first part of the word and the misunderstanding gets worse as he thinks she is inviting him to a sexual relationship. The word play is quite witty, but its translation does not really meet its wit. Instead of a single word 'unisex', five are used in Arabicterat and which actually cannot be exploited in any wordplay. In other words, the pun is lost. The wordplay on the 'sex' part of the word is manipulated given that the reference in Arabic remains vague. The word stated by Joey 'علاقة/relationship' is imprecise as it does not necessarily refer to sex. In fact, this imprecision is intended to create certain confusion for the audience. The pun is extended to a further scene:

Rachel: Don't listen to them. I think it's sexy.

Joey: You-and-1 sexy?

رايتشل: لا تنصت لهها /جذها جذابة

جوي :انت و انا جذابان

The laugh tracks in both scenes imply that the wordplay is strikingly successful. Unfortunately, the moral barriers imposed by the Arab culture make subtitlers helpless in front of such situations and push them to use manipulative strategies that most of the times usurp pun and humor out of these scenes.

Another witty wordplay occurs based again on the ignorance of a character of a particular word. Let's consider the following scenes:

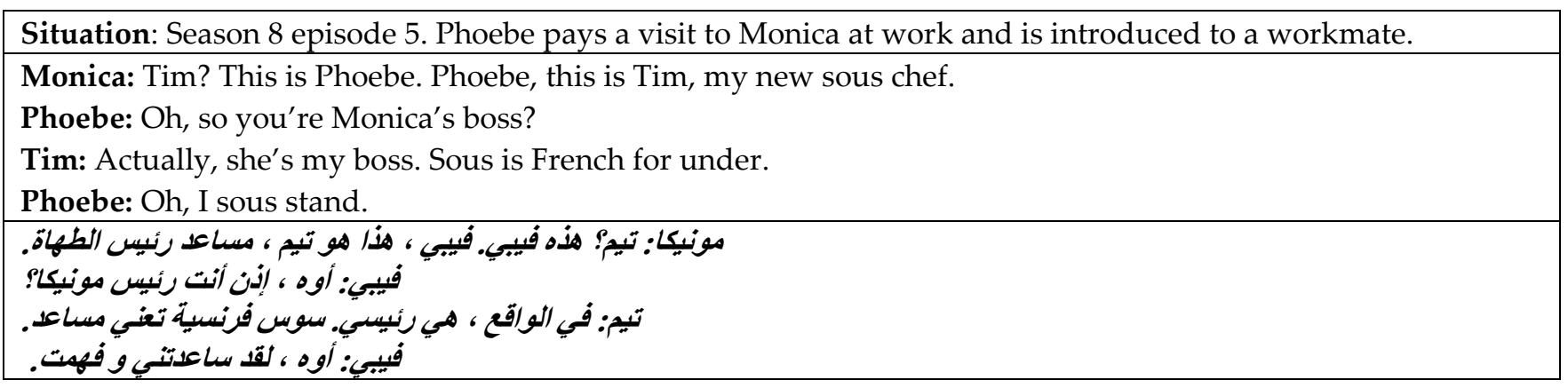

The pun in ST is with the French prefix 'sous' that Phoebe uses to make a witty word 'sous stand'. In the same way, the translator plays with the word ساعساعد and its derivation مساع . Though the humorous side of the joke is lost, the wordplay is maintained. Some scenes later, Phoebe uses the same pun again.

Phoebe: Uh Monica!I had the best time with Tim last night. He is so sweet. I can't wait to get'sous-neath' him. فيبي: آه مونيكا! قضيت أفضل وقت مع تيم الليلة الماضية. هو لطيف جذا. لا أطيق الانتظار حتى أراه.

Phoebe expresses her desire to have a sexual relationship with Tim. She uses the pun with 'sous' in an amusing way. As funny as the scene is, it is culturally not acceptable in the Arab context. Once again, the subtitler has to manipulate the taboo message and make it suitable to the target audience. The sentence أطيق الانتظار حتى أراه Ifalsely implies that Phoebe's feelings towards Tim are Platonic and that there is an innocent romance between the two: she cannot wait till she sees him. 
In fact, she openly states that she wishes for a sexual intercourse. Even in the American culture, Phoebe's statement' I can't wait to get 'sous-neath' him' is morally improper to be uttered by an ordinary decent American girl. Unfortunately, this witty wordplay is once again ignored and Phoebe's joke turns into an ordinary Arabic statement

\section{Conclusion}

Newmark (2003: 126-7) argues that, in principle, humor is universal, and can be, more or less, translated, provided that the source and target language readership or the listeners are educationally at the same level. He states that the problem in translating humor, regardless of the moral consideration, is just an issue in the different senses of humor translators may have. Chiaro (1992: 8), on the other hand, posits that vulgar jokes are considered amusing especially if they have sexual references. These types of jokes and puns are considered very offending in Middle Eastern societies as they are governed by a set of standards and values imposed by Islamic religion and tribal norms. Translating American humor into Arabic is problematic; subtitling it is even more challenging.

Subtitling humor on the screen, in general, is a difficult task for various reasons:

- The audiovisual text is multimodal.

- It is culture-based. The wider the gap between the two cultures is the harder to keep the humorous effect is.

- The spoken text undergoes an average 35\% reduction.

- The linguistic channel moves from informal/colloquial to formal/standard.

- The cultural norms of the source audience differ from the ones of the target audience.

- The professionals and patronage that monitor the act of subtitling are also governed by these cultural norms.

The above mentioned factors render the subtitler's task to translate humor an almost impossible mission. We have seen throughout the sequences discussed earlier that the subtitler has failed to translate the humorous part of speech. We have provided ten examples of humor: five jokes and five puns. All of them are extremely funny scenes in English. Not once has humor been kept in Arabic. The moral barriers imposed by the Arab culture make subtitlers helpless in front of such situations and push them to use manipulative strategies that most of the times usurp pun and humor out of these scenes. Three strategies are mostly used: loan, substitution and explicitation.

The series of Friends got its smashing fame thanks to the specificity of the makeup of each of the six characters who embody the controversial American moral and social issues in the 1990s and 2000s. They represent a sarcastically humorous criticism of youth's concerns including "same-sex marriage, artificial insemination, surrogate mothers, and age difference in romantic relationships" (Quaglio 2009: 77). This representation is molded in scripts based essentially on irony and wordplay. That is why; the subtitlers of the series find themselves in a real stalemate. Nearly, all the issues discussed in Friends are taboo in the Arab culture and the wordplay is as frequent as ordinary speech, so how can this dilemma be solved? In most cases, subtitlers favor 
the wordplay. Given that the taboo issues have to be manipulatively camouflaged or hidden, they try as far as they can to keep the puns though it is not always an easy task.

\section{Conflict of interest statement}

The authors declare no conflicts of interests.

\section{About the Author}

Abdelouahab Elbakri holds a PhD in translation studies from Ibn Zohr University in Agadir. He is a professor of English in Universiapolis in Agadir. He also works as a freelance translator.

\section{References}

Attardo, S. (1994). Linguistic Theory of Humour, Berlin-New York: Mouton de Gruyter.

Asimakoulas, D. (2004). Towards a Model of Describing Humour Translation: A Case Study of the Greek Subtitled Versions of Airplane! and Naked Gun, in Meta : journal des traducteurs, vol. $49, \mathrm{n}^{\circ} 4,822-842$.

Chiaro, D. (2009). Issues in audiovisual translation, in Jeremy Munday (ed.) The Routledge Companion to Translation Studies. London: Routledge, 141-165.

Díaz Cintas, J. and Aline, R. (2007). Audiovisual Translation: Subtitling. Manchester: St Jerome.

Díaz Cintas, J. (2012). Clearing the smoke to see the screen: ideological manipulation in audiovisual translation. In Díaz Cintas (ed.) The Manipulation of Audiovisual Translation, Meta special issue, 279-293

Dynel, M. (2009). Beyond a Joke: Types of Conversational Humour. In Language and Linguistics Compass, vol. 3, issue 5, 1284-1299

Gottlieb, H. (1997). Quality revisited: the rendering of English idioms in Danish television subtitles vs. printed translations. In Trosberg (ed.), 309-38.

Gottlieb, H. (2005). Language-political implications of subtitling. In Pilar Orero, ed. Topics in Audiovisual Translation, 83-100

Kostovčík , L. (2009). The Translation of Verbally-ExpressedHumour on Screen in Slovakia: An Outline of Research Problems, in Language, Literature and Culture in a Changing Transatlantic World, 175-180

Liebold, A. (1989). The Translation of Humour; Who says It Can't Be Done. META xxxv, 109-11

Locher, A. M. and Watts, J. R. (2005). Politeness Theory and Relational Work. Journal of Politeness Research, n¹, 9-33. http://dx.doi.org/10.1515/jplr.2005.1.1.9 Accessed on June 27th 2018

Newmark, P. (2003). Translation Now. The Linguist, 42: 4, 125-7.

Quaglio, P. (2009). Television Dialogue. The Sitcom Friends vs. Natural Conversation. Amsterdam: John Benjamins.

Toury, G. (1995). Descriptive Translation Studies and Beyond. Amsterdam: John Benjamins.

Vandaele, J. (2010). Humor in translation. In Yves Gambier and Luc Van Doorslaer (eds.). Handbook of translation studies. Volume 1. Amsterdam and Philadelphia: John Benjamins, 147-152. 
Creative Commons licensing terms

Author(s) will retain the copyright of their published articles agreeing that a Creative Commons Attribution 4.0 International License (CC BY 4.0) terms will be applied to their work. Under the terms of this license, no permission is required from the author(s) or publisher for members of the community to copy, distribute, transmit or adapt the article content, providing a proper, prominent and unambiguous attribution to the authors in a manner that makes clear that the materials are being reused under permission of a Creative Commons License. Views, opinions and conclusions expressed in this research article are views, opinions and conclusions of the author(s). and European Journal of Literature, Language and Linguistics Studies shall not be responsible or answerable for any loss, damage or liability caused in relation to/arising out of conflicts of interest, copyright violations and inappropriate or inaccurate use of any kind content related or integrated into the research work. All the published works are meeting the Open Access Publishing requirements and can be freely accessed, shared, modified, distributed and used in educational, commercial and non-commercial purposes under a Creative Commons Attribution 4.0 International License (CC BY 4.0). 